\title{
EL ANTIFEMINISMO DE EMILIA PARDO BAZÁN EN LAS NOVELAS DE LOS PAZOS
}

\author{
Por \\ ÁNGELES SANDINO CARREÑO
}

Estamos acostumbrados a que la crítica adopte una postura casi unánime al defender el feminismo de Emilia Pardo Bazán. Quizás, al evaluar su obra en conjunto, ésa podría ser la conclusión extraída de sus escritos, pero creo que existe una gran diferencia entre los artículos, ensayos y conferencias de doña Emilia, en los que abiertamente toma partido a favor de la igualdad de los sexos, y sus novelas, en las que, por no tener que exponer sus ideas, sino las de unos terceros, no cuida tanto su actitud combativa y deja escapar pequeños detalles que son lo suficientemente reveladores de que su feminismo es más teórico que real, y vendrían a corroborar lo expuesto por Marina Mayoral de que «el feminismo de doña Emilia chocaba con su conservadurismo social y por eso fue estéril» ${ }^{1}$.

Quede claro, no obstante, que trataremos de demostrarlo sólo en las novelas de Los Pazos, sin que esto conlleve a extraer conclusiones del resto de sus obras.

Para analizar esos pequeños detalles de los que hablamos, es importante partir de la falta de objetividad en las novelas de Emilia Pardo Bazán. Toda la crítica resalta cómo la escritora no se adecua a un principio bási-

'Marina Mayoral, Prólogo a Los Pazos de Ulloa, Castalia, Madrid, 1986, pág. 97.

"CUADERNOS DE ESTUDIOS GALLEGOS", Tomo XLIV, Fascículo 109, Santiago 1997. 
co del realismo y del naturalismo: la exposición objetiva de los hechos narrados, sin intervenciones del autor en la obra, que supongan una toma de postura acerca del tema que se trata, y conviertan así la novela en un género de tesis².

Porque doña Emilia en el prólogo de Un viaje de novios afirma que «la novela es traslado de la vida, y lo único que el autor pone en ella es un modo peculiar de ver las cosas reales» ${ }^{3}$, y con estas últimas palabras nos da una idea clara de la subjetividad latente en sus obras. A veces da la impresión de que la novela está en función de los pensamientos del autor y como apunta Varela Jácome, doña Emilia, en algunas ocasiones, «elabora los ambientes, el paisaje 'a priori', extrae la idea de sí misma y obliga a la realidad a confirmarla» ${ }^{4}$. La misma Pardo Bazán en Aficiones peligrosas afirma: «No tengo únicamente el objeto de mostrar las escenas como podría hacerlo con las vistas de un estroboscopio, sino de dirigir las reflexiones del lector hacia el fin moral que me propongo» ${ }^{5}$. Según W.T. Pattison «lo único en que la condesa difiere de los naturalistas consiste en su falta de impersonalidad. Deja ver sus entusiasmos y opiniones» ${ }^{6}$.

Para analizar esas incoherencias que demuestran ideas antifeministas en Emilia Pardo Bazán, nos centraremos en tres aspectos: el tratamiento que la autora da al personaje de Julián, las simpatías y antipatías que demuestra hacia algunos personajes, y las contradicciones existentes entre su forma de pensar y su obra.

No es mi intención hacer un estudio del inexperto capellán, cuando muchos críticos lo realizaron antes; no creo tener nada que añadir a lo ya estudiado por Marina Mayoral, Nelly Clemessy, Anthony Goosch, etc..., acerca del sacerdote de Los Pazos de Ulloa. Mi análisis se reducirá a

\footnotetext{
${ }^{2}$ Sobre impersonalidad y subjetividad narrativas, consúltese: Nelly Clemessy, Introducción a su edición de Los Pazos, págs. 51-61. De Germán Gullón, El narrador en la novela del siglo XIX, Taurus, Madrid, 1976; del mismo autor, «La densidad genérica y la novela del ochocientos: Los pazos de Ulloa de Emilia Pardo Bazán», en Anales de literatura española 5 (1986-1987), págs. 173-188.

${ }^{3}$ Emilia Pardo Bazán, Prólogo a Un viaje de novios, Labor, Barcelona, 1971, págs. 57-62.

${ }^{4}$ Benito Varela Jácome, «Romanticismo en tres novelas de Emilia Pardo Bazán», Cuadernos de Estudios Gallegos, Tomo XXIV (1969), pág. 316.

${ }^{5}$ E. Pardo Bazán, Aficiones peligrosas, Recopilación y estudio de Juan Paredes Núñez, Palas Atenea, Madrid, 1989, págs. 41-42.

${ }^{6}$ W.T. Pattison, El Naturalismo Español, Gredos, Madrid, 1969, pág. 105.
}

"CUADERNOS DE ESTUDIOS GALLEGOS", Tomo XLIV, Fascículo 109, Santiago 1997. 
evidenciar aquellos aspectos en los que creo encontrar una coincidencia entre él y doña Emilia; por tanto no trataré muchas de las características del personaje porque no corresponden al estudio que nos ocupa. Para conocer mejor la personalidad y el retrato del sacerdote, remitiré al lector a los críticos ya apuntados que trataron ampliamente el tema ${ }^{7}$.

Julián es el personaje central de Los Pazos de Ulloa y portavoz de las ideas de la novelista, pero también será motivo de burla en todos aquellos aspectos en los que doña Emilia no se identifique con él; en este último caso el narrador tomará la batuta de la representación y se erigirá en director de los acontecimientos e ideas que se expongan, llegando incluso en algunos momentos a permitirnos ver en sus palabras en vez del narrador, a la narradora. Según Darío Villanueva «el narrador [...] no queda totalmente desdibujado en la modalidad omnisciente selectiva» ${ }^{8}$ y Carlos Feal lo matizará indicando que «no sólo [...] no queda totalmente desdibujado sino que está en ocasiones muy presente para exponer una actitud marcadamente femenina, o, más aún, feminista»9.

En La Madre Naturaleza Julián cederá el puesto de narrador oculto a Gabriel Pardo, que toma el hilo conductor de la novela, y al final de la misma observaremos las opiniones encontradas que estos dos personajes tienen acerca de un mismo tema, y la solución final inclinará al lector a pensar que, a pesar de haberlo utilizado como portavoz en esta segunda novela, a la hora de decidirse, doña Emilia retoma a Julián, plenamente identificada con su misión evangelizadora, como representante de sus opiniones.

Marina Mayoral afirma que el intento evidente de mantener la impersonalidad, sólo lo consigue Emilia Pardo Bazán en algunos relatos breves, pero «con gran frecuencia en sus relatos largos intercala opiniones y

\footnotetext{
${ }^{7}$ Consúltese: Marina Mayoral, prólogo a su ed. de Los Pazos..., Ob. cit.: de la misma autora, Estudios sobre «Los Pazos de Ulloa», Madrid, Cátedra, 1989; Nelly Clémessy, prólogo a su ed. de Los Pazos..., Espasa Calpe, Madrid, 1987; Anthony Gooch, «Análisis psico-somático de un personaje de Los Pazos de Ulloa y La Madre Naturaleza de Emilia Pardo Bazán: Julián», en En torno a Pemán, Cádiz, Diputación Provincial, 1974, págs. 443-468.

${ }^{8}$ Darío Villanueva, «Los Pazos de Ulloa, el naturalismo y Henry James», Hispanic Review, vol. 52, núm. 2 (Spring 1984), págs. 121-139.

${ }^{9}$ Carlos Feal Deibe, «La voz femenina en Los Pazos de Ulloa», Hispania, 70 (mayo 1987), pág. 214.
}

"CUADERNOS DE ESTUDIOS GALLEGOS", Tomo XLIV, Fascículo 109, Santiago 1997. 
observaciones que traslucen claramente su ideología, sus fobias y filias ${ }^{10}$. Comparto plenamente esta afirmación y trataré de desmenuzar los pormenores que me llevan a corroborarla en lo que se refiere a las obras de Los Pazos.

Son múltiples las ocasiones en que podemos entrever a Emilia Pardo Bazán en su personaje.

Para no alargar la exposición trataré de esquematizar al máximo los puntos de contacto entre personaje y autor.

a) Las diferencias de clase: Son conocidas las ideas de Emilia Pardo Bazán con respecto a la clase social a la que pertenece y al desprecio que manifiesta hacia las clases inferiore ${ }^{11}$. Julián se hace eco de estas opiniones en algunos episodios de Los Pazos de Ulloa; así, cuando increpa al marqués por mantener relaciones con una simple criada (cap. VIII), no censurando tanto el hecho pecaminoso, como la clase de la persona con quien se lleva a cabo; por eso le aconseja ir a Santiago donde hay «tantas señoritas buenas y honradas» y podrá casarse «con persona de su esfera» $(\mathrm{P}, 196)^{12}$. Más adelante, cuando se requiere la presencia de un ama de cría y don Pedro trae por la fuerza a una mujer recién parida, Julián responde a las críticas sociales del médico Juncal, que juzga esto negativamente, elogiando la idea de don Pedro que, al traerla, le dará un trabajo en una casa de bien, en la que se encontrará «bien mantenida, bien regalada» $(\mathrm{P}, 281)$.

Julián no pertenece a una clase social alta, pero ha convivido con ella y ha asimilado los postulados de ésta: «Yo me crié en esta casa, es cierto; pero sin manualizarme con los señores, porque mi clase era otra muy distinta...» (P, 219). También Gabriel Pardo en La Madre Naturaleza increpará a Perucho por pretender a Manolita, superior a él en clase: « $i \mathrm{Y}$ siendo sus padres de usted..., un mayordomo y una criada..., cómo se ha

\footnotetext{
${ }^{10}$ Marina Mayoral, Prólogo a su ed. de Los Pazos..., Ob. cit., págs. 30-31.

"Carlos F. Velasco Souto, A sociedade galega da Restauración na obra literaria de Pardo Bazán (1875-1900), Artes gráficas Portela, Pontevedra, 1986, pág. 32.

12 Todas las citas que se hacen de las dos novelas en este trabajo corresponden a las siguientes ediciones:

Los Pazos de Ulloa, Edición de Marina Mayoral, Castalia, Madrid, 1986.

La Madre Naturaleza, Edición de Ignacio J. López, Taurus, Madrid, 1992.

Las referencias a las páginas se indicarán entre paréntesis, precedidas de P o M según se trate de uno u otro libro.
}

"CUADERNOS DE ESTUDIOS GALLEGOS", Tomo XLIV, Fascículo 109, Santiago 1997. 
atrevido usted..., a poner los ojos en mi sobrina?» (M, 324). Pero en estas palabras podemos vislumbrar un debilitamiento de tales ideas, quizás porque Gabriel las utiliza ya sabiendo el parentesco entre Perucho y Manolita, quizás porque la misma doña Emilia se da cuenta de que ese no sería el principal problema para su relación.

b) La higiene: Nelly Clemessy ${ }^{13}$ advierte cómo doña Emilia identifica limpieza corporal con limpieza de espíritu. De esto se hace eco también Julián, para quien la limpieza es esencial. En Los Pazos de Ulloa la suciedad que encuentra a su alrededor le infunde «grandes deseos de primor y de limpieza, una aspiración a la pulcritud en la vida como a la pureza en el alma» $(\mathrm{P}, 145)$. Contrasta el aseo exagerado del sacerdote con la falta de higiene de su antecesor que, por lo que puede observar, no tenía mucho que ver con la higiene y «consideraba artículo de lujo los enseres de tocador, pues no vio Julián por allí más que una palangana de hojalata [...]. Ni jarra, ni toalla, ni jabón, ni cubo» $(\mathrm{P}, 147)$. El contraste entre el abad de Ulloa, que nunca sintió la necesidad de que le barrieran la habitación $(\mathrm{P}, 148)$ y Julián, que considera que «la limpieza es una cosa que a todo el mundo gusta» (P, 148), es evidente; ese contraste se da también en el trato abiertamente hostil por parte del abad, que lo juzga negativamente por su manía del aseo: «Al abad de Ulloa [...] le exasperaba Julián, a quien solía apodar mariquitas; porque para el abad de Ulloa, la última de las degradaciones en que podía caer un hombre era beber agua, lavarse con jabón de olor y cortarse las uñas» $(\mathrm{P}, 173)$.

Julián rechaza casi sin darse cuenta a todo aquel que muestre poca limpieza corporal, pero sobre todo si se trata de una mujer, como ocurre con Sabel, que siempre se presenta ante él con escaso aseo. Julián «huele» el olor a cama que desprende Sabel (P, 147). Fijémonos en que no hay referencias al rechazo de los personajes masculinos (excepto el abad) por su poca higiene; incluso podríamos decir que a veces se alaba: «venía el marqués varonilmente desaliñado» $(\mathrm{P}, 133)$, pero es automáticamente motivo de rechazo en la mujer. Inconscientemente doña Emilia comprende la suciedad en el hombre, pero es incapaz de admitirla en la mujer, sin que aquella conlleve otros vicios, como la falta de moralidad.

\footnotetext{
${ }^{13}$ Nelly Clemessy, Emilia Pardo Bazán como novelista, Fundación Universitaria Española, Madrid, 1981, Tomo II, pág. 806.
}

"CUADERNOS DE ESTUdIOS GALLEGOS", Tomo XLIV, Fascículo 109, Santiago 1997. 
c) El matrimonio: Para Julián el matrimonio es sagrado, y, como tal, debe mantenerse alejado de devaneos extramaritales. La sexualidad es algo puramente secundario en una institución en la que deben prevalecer el cariño y la ternura de los esposos por encima de todo: «La índole de tan sagrada institución — discurría Julián - es opuesta a impúdicos extremos y arrebatos, a romancescos y necios desahogos, ardientes y roncos arrullos de tórtola» (P, 258). Además el matrimonio tiene en sí la posibilidad de armonizar la religión y el sexo, es el «lazo bendito, por medio del cual la Iglesia atiende juntamente, con admirable sabiduría, a fines espirituales y materiales, santificando los segundos por medio de los primeros» (P, 257-258).

Doña Emilia participa de todas estas opiniones del sacerdote y comparte con él la idea del matrimonio; cuando D. Pedro va a ser padre, trata a Nucha con toda la amabilidad y dulzura de que es capaz: le trae flores, impide los escopetazos porque la sobresaltan, da paseos con ella... Todo esto lleva a la escritora a sentenciar: «Si aquello no era el matrimonio cristiano soñado por el excelente capellán, viven los cielos que debía de asemejársele mucho» (P, 274).

Según Pilar González Martínez ${ }^{14}$, Emilia Pardo Bazán reivindica para la mujer la libertad de elección del cónyuge. El matrimonio sin amor supone un verdadero holocausto para la mujer. El matrimonio en sí significa además el fín del amor o del deseo sexual.

d) Espiritualidad: Julián une a su inocencia e ingenuidad una buena dosis de espiritualidad ${ }^{15}$. A pesar de querer a Nucha y a su hija más que al resto de los que le rodean, no se siente apegado a las cosas de este mundo; es un ser puro, que apenas ha tenido contacto con la sociedad y que en algunos momentos se siente «mortificado por la repugnancia que le inspiran las cosas exclusivamente materiales» $(\mathrm{P}, 183)$; cuando en la mesa se entrecruzan bromas subidas de tono que ofenden su pudor o el de las personas que quiere, trata de contrarrestarlas con lecturas piadosas que lo alejan del ambiente soez que le rodea. En el sacerdote la influencia del

\footnotetext{
${ }^{14}$ Pilar González Martínez, Aporías de una mujer, Emilia Pardo Bazán, Madrid, Siglo XXI, 1988, pág. 88.

${ }^{15}$ Sobre la espiritualidad de Julián consúltese: Mariano López, «Naturalismo y espiritualismo en Los Pazos de Ulloa», en Revista de Estudios Hispánicos, 12, 3 (Oct. 1978) págs. 353-371.
}

"CUADERNOS DE ESTUDIOS GALLEGOS", Tomo XLIV, Fascículo 109, Santiago 1997. 
medio no actúa como en los demás personajes: la naturaleza no lo embrutece, sino que lo mantiene con más fuerza en su ser inicial; Marina Mayoral lo cita, junto a Ramón Limioso, como los dos pesonajes «que mantienen sus posturas espirituales y refinadas pese a la brutalidad general» ${ }^{16}$. En La Madre Naturaleza su espiritualidad se acrecienta, sus actos llevan a Juncal a afirmar: «Si todos fuesen como ese, me parece que acabaría por volverme beato» $(\mathrm{M}, 150)$; y el narrador añade que «se veía con él la anulación del cuerpo» (M, 236), así pues, el sacerdote es sólo espíritu.

No tendremos que recordar aquí otra vez las teorías expuestas por Emilia Pardo Bazán acerca de la dualidad del hombre: cuerpo y espíritu, ni volver a repetir la opinión que doña Emilia alberga sobre la indiscutible superioridad del espíritu sobre lo fisiológico ${ }^{17}$. La solución que se da al conflicto planteado en La Madre Naturaleza habla por sí sola: «La ley de la naturaleza, aislada, sola, invóquenla las bestias: nosotros invocamos otra más alta. Para eso somos hombres, hijos de Dios y redimidos por él» (M, 375).

Entremos ahora en el segundo aspecto que advertíamos en Julián, como objeto de burla por parte del narrador. Dos son las características negativas que doña Emilia resalta en Julián: su apariencia física y su debilidad de carácter. Inmediatamente nos preguntamos cuál es la intención de la autora al burlarse de su personaje principal, el que le sirve de portavoz a muchas de sus ideas. Me parece que la contestación la encontraremos mirando los principios del realismo; doña Emilia quiere pintar un personaje real, con virtudes, pero también con defectos, aunque estos últimos sean sólo externos y no dañen la integridad del personaje. Julián me parece el ser más real de las dos obras, en el que se mezclan lo bueno y lo malo; todos los demás militan en un solo bando y, aunque están bien retratados, parecen mostrársenos en una sola de sus facetas, la que interesó en cada caso a la autora; quizás me explicaría más claramente diciendo que los personajes están vistos de lado, desde un solo ángulo, quedando los demás ocultos al lector.

\footnotetext{
${ }^{16}$ Marina Mayoral, Prólogo a Los Pazos..., Ob. cit., pág. 28.

${ }^{17}$ Sobre este particular consúltese: Donald Fowler Brown, The catholic Naturalism of Pardo Bazán, University of North Carolina Studies in the Romance Languages and Literatures, vol. 28, Chapel Hill, 1957.
}

"CUADERNOS DE ESTUdIOS GALLEGOS", Tomo XLIV, Fascículo 109, Santiago 1997. 
En lo que concierne al aspecto físico Julián se nos presenta como un joven de «miembros delicados», y semejante a un niño «por no tener pelo de barba» $(\mathrm{P}, 127)$. Observaremos que esa cara de niño quiere sugerir su inocencia, más que su excesiva juventud. Al empezar la obra se nos dice de él que iba «colocado, no como un pimiento, sino como una fresa, encendimiento propio de personas linfáticas» $(\mathrm{P}, 127)$.

Si los datos ofrecidos del personaje resultan suficientes para darnos la idea de un ser enclenque, esto se realza al contraponerlo a la figura fuerte y varonil de los tres hombres que le salen al encuentro: el marqués, el abad de Ulloa y Primitivo. Cuando más adelante se nos añade que el sacerdote no bebe y tiene un cuidado excesivo por la higiene, comprendemos que la intención de doña Emilia ha sido identificarlo con una mujer, sin llegar a caer en ningún momento en el tema de la homosexualidad. Carlos Feal afirma que la.voz de la narradora se funde con la de Julián, y que esta fusión se hace posible gracias a la «descripción hecha de Julián como un individuo afeminado o dotado de una sensibilidad femenina» ${ }^{18}$. Si en algún momento llegáramos a pensar que doña Emilia da a su personaje rasgos femeninos por tratarse de un sacerdote, esto queda literalmente rechazado al leer la descripción hecha del abad del Ulloa, con la «tonsura borrada por una selva de pelo gris y cerdoso» y con «duros cañones de su azulada barba» $(P, 132)$ que contaban un mes de antigüedad. Vestido sin alzacuello, con botas de montar, es cazador y bebedor, lo cual no le impide ser sacerdote. Se sirve Pardo Bazán de este personaje para incidir en la descripción de Julián: «Curita barbilindo, con cara de niña, donde sólo era sacerdotal la severidad del rubio entrecejo y la compostura ascética de las facciones» $(\mathrm{P}, 134)$; dice de él que es un «miquitrefes» (P, 135) y más tarde le llamará «mariquitas» $(\mathrm{P}, 173)$.

Esta insignificante apariencia va unida a sus pocas habilidades físicas. En el primer capítulo de Los Pazos de Ulloa se nos presenta como un pésimo jinete al que el caballo dirige, como y hacia donde quiere, mientras él se preocupa de no caerse y de calarse el sombrero «hasta las cejas» $(\mathrm{P}, 128)$ para que no vuele en uno de los bruscos movimientos. Más adelante observamos que tampoco es buen cazador. Los cazadores se burlan de su atuendo «porque iba vestido de modo asaz impropio para la oca-

\footnotetext{
${ }^{18}$ Carlos Feal, «La voz femenina...», Art. cit., pág. 215.
} 
sión, sin zamarra, ni polainas de cuero, ni sombrerazo, ni armas ofensivas o defensivas de ninguna especie» $(\mathrm{P}, 331)$, y cuando da muestra de sus nulas habilidades como cazador, el narrador insiste en burlarse de él al hacer que el perro de caza, el Chonito, «clavando en el capellán una mirada casi humana, llena de desprecio» (P, 333), se aleje, rechazando servir de compañía a tan inútil sujeto.

Julián, así retratado, no es un antihéroe, sino, como dice Marina Mayoral, «el héroe tragicómico» ${ }^{19}$, estableciéndose una clara diferencia con el héroe romántico, que nunca es motivo de risa.

Otro aspecto que se resalta es su debilidad de carácter: Julián es un hombre criado en un pueblo, y el encuentro con la naturaleza le produce indiscriptible confusión, unida a un miedo atroz; miedo a los ruidos, a lo desconocido, a encontrarse inmerso en un medio agreste: «Quedóse el jinete frío de espanto, agarrado al arzón, sin atreverse ni a registrar la maleza para averiguar dónde estarían ocultos los agresores» (P, 131). Esta característica de Julián aparecerá reiteradamente en la obra para resaltarla como identificativa del personaje; así la encontramos de nuevo en el capítulo XII: «Estremecióse Julián, y se le borraron las rosadas tintas de los pómulos. No era de madera de héroe, lo cual le salía a la cara. A don Pedro le divertía infinito el miedo del capellán». Curiosamente, en este épisodio el narrador nos dice que a causa de la lluvia estaba el terreno encharcado y los árboles dejaban caer los restos de agua almacenada en sus hojas, y en ese momento Julián «iba perdiendo el miedo, y un gozo muy puro le inundaba el espíritu». El agua aparece sugiriendo en este caso que, igual que limpia la naturaleza, se limpia el espíritu de Julián; tendríamos un agua purificadora, muy distinta de la que encontramos en otros momentos de la obra.

Doña Emilia, para resaltar la debilidad del personaje y su poco carácter nos lo presenta tratando de calmar a un caballo demasiado vehemente «susurrando palabrillas calmantes y mansas» $(\mathrm{P}, 127)$; el diminutivo empleado tomará forma después al contrastarlo con la fuerza de la naturaleza en la que se encuentra; Julián, parece decirnos la autora, es un iluso que trata suavemente a quien hay que guiar con mano dura, lo cual es prueba evidente de su poco carácter. Como dice el marqués de él en un

${ }^{19}$ Marina Mayoral, Prólogo a su ed. de Los Pazos..., Ob. cit., pág. 56.

"CUADERNOS DE ESTUDIOS GALLEGOS", Tomo XLIV, Fascículo 109, Santiago 1997. 
primer contacto, «no mete respeto» $(\mathrm{P}, 135)$ y más adelante, en el capítulo VII, al dirigirse al sacerdote, le dice: «es usted un infeliz, es usted demasiado bonachón».

Julián ha sido educado bajo el ala protectora de su madre, que parece haberle contagiado las características femeninas que observamos en su personalidad. «Julián pertenecía a la falange de los pacatos, que tienen la virtud espantadiza, con respulgos de monja y pudores de doncella intacta. No habiéndose descosido jamás de las faldas de su madre [...] sabía de la vida lo que enseñan los libros piadosos (P, 145-46). Por eso su carácter es débil, parece decir la autora, como el de una mujer. «iQué trazas de mujercita tiene este cura! ¿Qué poquito estuche!» $(\mathrm{P}, 58)$, exclama Juncal al saber del desmayo que ha sufrido la noche en que Nucha padece los dolores del parto; y recordemos que también Juncal sirve en algunos momentos de portavoz a la escritora.

Todas estas burlas en cuanto al físico y al carácter del sacerdote, llevan a Carlos Feal a afirmar que «desde una actitud que podría calificarse de machista, la narradora se burla constantemente de Julián, o lo increpa debido a su afeminamiento ${ }^{20}$. Marina Mayoral se fija en el tratamiento irónico que doña Emilia da a muchos personajes secundarios, pero de entre los importantes «sólo con don Julián hace el narrador uso constante de la ironía o la burla ${ }^{21}$ y sólo al final de la obra el personaje perderá su carácter cómico «para ser solamente un personaje trágico, carácter que mantendrá en La Madre Naturaleza» ${ }^{22}$.

Y nos podríamos preguntar: si Julián es el personaje principal, si sirve de hilo conductor a las opiniones del autor, si en La Madre Naturaleza la tesis que defiende es la de doña Emilia, y, si la Condesa es tan feminista, ¿por qué este empeño en burlarse del personaje asemejándolo a una mujer? ¿Tendríamos que deducir, por otra parte, que la debilidad de carácter es un rasgo propio de las hembras? Creo que es un comentario sexista el que doña Emilia expone acerca de las mujeres en la descripción que hace de Julián en el capítulo III:

\footnotetext{
${ }^{20}$ Carlos Feal, «La voz...», Art. cit., pág. 215.

${ }^{21}$ Marina Mayoral, Prólogo a su ed. de Los Pazos..., Ob. cit., pág. 56.

${ }^{22}$ Idem, pág. 59.
}

"CUADERNOS DE ESTUDIOS GALLEGOS", Tomo XLIV, Fascículo 109, Santiago 1997. 
«La endeblez de su temperamento linfático-nervioso, puramente femenino, sin ardores ni rebeldías, propenso a la ternura, dulce y benigno como las propias malvas, pero no exento en ocasiones de esas energías súbitas que también se observan en la mujer, el ser que posee menos fuerza en estado normal y más cantidad de ella desarrolla en las crisis convulsivas» $(\mathrm{P}, 146)$.

Todo esto nos lleva a pensar que doña Emilia considera a la mujer de temperamento linfático-nervioso, y como ejemplo, Nucha. De esto deduciremos que la que no pertenezca a este grupo no es representativa del ser femenino, o que, al menos, existe en ella algo que la aparta del prototipo. De la misma forma, el hombre tiene un temperamento más violento y pasional, y el que no manifiesta estas características, como Julián, no tiene cabida entre los de su sexo, y se queda a medio camino entre uno y otro. Resulta interesante observar cómo en el capítulo XXIX de Los Pazos, en la violenta escena vivida por Julián en la capilla, su arranque de genio, encarándose con el marqués, y su indignación ante las monstruosas sospechas que don Pedro lanza contra Nucha y contra él, llevan al narrador a decir que Julián retó a aquél «de hombre a hombre» (P, 405), y subraya las palabras como sugiriendo que el arranque de valor le ha permitido tal apelativo; no creo que en este momento doña Emilia haya querido ridiculizar al personaje aludiendo a su falta de virilidad, ya que no encajaría dentro del dramatismo de la escena; más bien ha recompensado al sacerdote, concediéndole lo que hasta ese momento le había negado: su hombría. En La Madre Naturaleza Julián continúa con esta característica conseguida al final de la novela anterior, porque el retiro del mundo y el alejamiento de las personas le han permitido endurecer su carácter.

Establece, pues, la escritora una clara oposición entre los seres basada en el sexo y considera que las diferencias entre hombre y mujer van más allá de lo puramente fisiológico.

En cuando a las simpatías y antipatías, a simple vista se observa el mayor o menor agrado con que Emilia Pardo Bazán ha retratado a sus personajes. Distinguimos personajes positivos, negativos y neutros; estos últimos los catalogaremos así, no porque no estén bien retratados, sino porque la escritora no se define suficientemente en su inclinación o rechazo; serían los más reales, además de Julián.

"CUADERNOS DE ESTUdios GALLEGOS", Tomo XLIV, Fascículo 109, Santiago 1997. 
P. Positivos $\begin{cases}\text { Masculinos } & \left\{\begin{array}{l}\text { Julián } \\ \text { Perucho } \\ \text { Gabriel }\end{array}\right. \\ \text { Femeninos } & \left\{\begin{array}{l}\text { Nucha } \\ \text { Manolita } \\ \text { Catuxa }\end{array}\right.\end{cases}$

P. Negativos $\left\{\begin{array}{l}\text { Masculinos }\left\{\begin{array}{l}\text { Primitivo } \\ \text { El Gallo }\end{array}\right. \\ \text { Femeninos }\left\{\begin{array}{l}\text { Sabel } \\ \text { La Sabia } \\ \text { El Ama de cría }\end{array}\right.\end{array}\right.$

P. Neutros $\begin{cases}\text { Masculinos } & \left\{\begin{array}{l}\text { D. Pedro Moscoso } \\ \text { D. Manuel de La Lage } \\ \text { Los Curas } \\ \text { Los Caciques } \\ \text { Juncal }\end{array}\right. \\ \text { Femeninos } & \left\{\begin{array}{l}\text { Las señoritas de La Lage }\end{array}\right.\end{cases}$

"CUADERNOS DE ESTUDIOS GALLEGOS", Tomo XLIV, Fascículo 109, Santiago 1997. 
Entre los personajes positivos, dos actúan de narradores encubiertos y sirven de eco a las ideas de la autora (Julián y Gabriel) y el otro (Perucho) actúa de portavoz de doña Emilia en la última parte de Los Pazos de Ulloa, dejándonos ver al mismo tiempo el alcance que tienen los hechos al ser narrados a través de los ojos de un niño. Cuenta con toda la simpatía de la autora, no sólo durante su infancia en Los Pazos de Ulloa, sino también en su edad adolescente, relatada en La Madre Naturaleza. En esta segunda novela Pardo Bazán lo ve con esa mirada indulgente con que se observa a un joven hermoso, sano y fuerte, que cuenta además entre sus virtudes con la ternura, la comprensión y la consideración hacia el ser amado. Perucho es a los ojos de doña Emilia el prototipo de hombre, en el que se unen características propias de su sexo (valentía, fuerza física, hombría...) con las del contrario (sensibilidad, ternura, cariño, sacrificio). Carlos Feal identifica a Julián y a Perucho y dice de ellos que son «personajes andróginos, cuya virilidad no está reñida con la aparición de características del sexo (pretendidamente) opuesto» ${ }^{23}$. No obstante, creo que esto sólo rezaría con Perucho, del que no existe en ninguna de las dos novelas el más mínimo comentario peyorativo, si no es la insinuación de su escasa afición al estudio, y aun esto vendría dado porque aprender supone para él el suplicio de alejarse de Manola.

Entre los personajes femeninos se encuentran: Nucha, personaje con quien se identifica doña Emilia; Manola, ser natural y de conducta recta, tan diferente y $\tan$ parecida a su madre; y Catuxa, suave y hogareña. Notamos que las tres tienen en común el cariño y la ternura hacia los seres que aman: en Nucha el amor maternal, en Catuxa la atención y cuidado a su esposo, en Manolita la admiración hacia Perucho y el abandono de su ser en el de él. En todas ellas destaca la capacidad de sacrificio: Nucha casándose sin amor, Catuxa dejando su trabajo en el molino, Manolita renunciando a la vida y encerrándose en un convento. De ninguna de ellas hay comentarios negativos, en todo caso se sugiere la falta de intelectualidad de Catuxa.

Entre los personajes negativos, Primitivo es el compendio de todos los defectos achacables al campesinado gallego; no nos ocuparemos de su estudio individualizado, demasiado extenso y ajeno al tema que nos

${ }^{23}$ Carlos Feal, «La voz...», Art. cit., pág. 220.

"CUADERNOS DE ESTUDIOS GALLEGOS", Tomo XLIV, Fascículo 109, Santiago 1997. 
ocupa. El Gallo, por su parte, es un personaje ridículo, despreciable para el narrador por el papel que desempeña en los Pazos; es objeto de burla por sus deseos de ascender en la escala social. La Sabia y el ama de cría son mujeres del pueblo que sirven a Emilia Pardo Bazán como excusa para desarrollar los postulados del naturalismo (gusto por lo feo y por los seres patológicos o repugnantes) o para desarrollar sus habilidades en el manejo del retrato caricaturesco. Pero el personaje negativo por excelencia y a quien dedicaremos un mayor apartado, por concentrarse en él muchos de los prejuicios escondidos de doña Emilia, es Sabel, la hija de Primitivo. Antes de detenernos en su estudio, me interesa hacer notar cómo los personajes que hemos agrupado en el apartado de neutros pertenecen, en general, a la clase media o media-alta (la misma en la que están los positivos), pero algún defecto los relega a ese apartado; tal es el caso del marqués (brutal, adúltero), de D. Manuel Pardo (interesado, calculador), de los curas (glotones, maledicentes), los caciques («ninguno de los dos adversarios tenía ideas políticas» $\mathrm{P}, 345$ ), Juncal (bebedor y ateo) o incluso Rita y sus hermanas (muñecas de salón y mozas casaderas ante todo). A simple vista parece que hay personajes buenos y personajes malos, y un grupo en el que se encuentran los que mezclan características positivas y negativas, y que son, como ya dije antes, los más reales.

Emilia Pardo Bazán no es objetiva cuando traza el retrato de Sabel. No incidiremos en las características de este personaje, sólo explicaremos datos que sirvan para evidenciar la animadversión de la escritora hacia el tipo de mujer que representa Sabel.

Empieza la autora por mostrarnos a Sabel-madre, antes que a Sabelsímbolo sexual. Observamos, después de comparar a las dos madres que aparecen en las novelas (Sabel y Nucha) la diferencia que existe entre ambas y que sirve a Pardo Bazán para establecer dos categorías de mujer de acuerdo con el desempeño de su función maternal.

Pilar González ${ }^{24}$ dice que para La Condesa existen:

- La madre por excelencia, que se sitúa del lado del espíritu, de la ciudad, de la muerte, y que simboliza en la Virgen madre. El retrato se conseguirá con la desmaterialización del cuerpo, deteniéndose sólo en el rostro (Nucha).

\footnotetext{
${ }^{24}$ Pilar González Martínez, Aporías de..., Ob. cit., págs. 44-53.
} 
- La mala madre, proyectada en los significantes carne-materia-campo-vida y que identifica con los animales (Sabel). Y el cuerpo como carne, insiste Pilar González, tendrá para Pardo Bazán las connotaciones peyorativas de la bestia, porque doña Emilia confunde el instinto con el deseo.

Notamos cómo en el capítulo II de Los Pazos de Ulloa, Perucho es confundido por Julián con los perros del marqués, a quienes disputa la comida; su madre no se ocupa de él y, como bestia que es, permite que su hijo viva como un animal. En contraposición a esta actitud encontramos a Nucha, siempre preocupada por su vástago, temerosa de que le pueda ocurrir cualquier daño, poniendo todos los medios a su alcance para que esto no ocurra; incluso rompe las normas sociales que le imponen sumisión y obediencia al marido, al que está dispuesta a abandonar por amor a su hija.

Estas dos madres se caracterizan además por actitudes y temperamentos distintos: la buena madre se dedica por entero a su hijo, abandonando cualquier otra pasión amorosa, lo que respondería a un personaje tranquilo y sin deseos sexuales, mientras que la mala madre tiene un temperamento agitado y pasional, y la mente puesta en las cosas de la carne, no en las del espíritu. González Martínez identifica correctamente quietud de espíritu con ausencia de deseo, y temperamento sanguíneo con sexualidad; en el caso de Sabel, sexualidad lujuriosa.

Después de haber conocido a Sabel como madre de Perucho, la conocemos como símbolo de la carnalidad, al denominarla con esa palabra exacta, «pedazo de lozanísima carne», en el segundo capítulo de Los Pazos de Ulloa. A partir de ese momento sus apariciones en escena harán referencia a su atractivo físico y a su falta de moral. Para ahondar en esta imagen, nos presenta al personaje en la cocina, inmediatamente después de hacer la descripción de los chorizos, jamones, etc... que cuelgan de las paredes. Casi siempre encontramos a la mujer asociada a la comida, al alcohol o al fuego, elementos que para la escritora son desencadenantes del deseo sexual. Efectivamente, en el capítulo al que hicimos referencia, Sabel, después de comer y beber, empieza a comportarse con mayores libertades que antes; es en ese momento cuando el narrador, a través de los ojos de Julián, nos presenta físicamente al personaje. Al ser el sacerdote prototipo de hombre casto y puro, las consideraciones negativas que hace de Sabel serán significativas e importantes para el retrato del perso-

"CUADERNOS DE ESTUDIOS GALLEGOS", Tomo XLIV, Fascículo 109, Santiago 1997. 
naje femenino. Utiliza aquí Emilia Pardo Bazán un recurso ya expuesto, consistente en presentar a un personaje a través de lo que otro piensa de él; así consigue caracterizar a dos seres sin intervenir en la narración, con lo que la supuesta objetividad del escritor, quedaría a salvo.

Carlos Feal afirma que «hay momentos en que la voz narradora, lejos de expresarse en términos femeninos o de fundirse con la voz del sacerdote, coincide extrañamente con la de la sociedad masculina reflejada en la novela ${ }^{25}$; éste es el caso de Sabel, hacia quien Julián siente un rechazo inmediato, como dice el narrador «a pesar o quizás a causa de que Sabel era un buen pedazo de lozanísima carne» $(\mathrm{P}, 141)$. El rechazo se convierte en repugnancia después de la escena en que la criada trata de embaucarlo con sus mañas (cap. V), hasta el punto de considerarla el pecado personificado: «No, no era Dios, sino el pecado, en figura de Sabel, quien lo arrojaba del paraíso» (P, 198), y aunque sabe que la chica tiene «un alma, redimida por la sangre de Cristo» es incapaz de sentir simpatía hacia una mujer desaseada, impúdica y que se parece tan poco a las mujeres que él conoce.

«¿Cómo podía haber mujeres así? Julián recordaba a su madre, tan modosa, siempre con los ojos bajos y la voz almibarada y suave, con su casabé abrochado hasta la nuez, sobre el cual, para mayor recato, caía liso, sin arrugas, un pañuelito de seda negra. ¡Qué mujeres! ¡Qué mujeres se encuentran por el mundo!» $(\mathrm{P}, 171)$.

Observemos la ironía con que doña Emilia retrata a determinado tipo de mujeres cursis y ñoñas, antítesis de Sabel. Son los dos extremos y estos, parece decir, nunca son aconsejables.

Además, para Julián, Sabel es un motivo de intranquilidad cada vez que fija en él «sus ojos azules, anegados en caliente humedad» (P, 167); nótense las connotaciones sexuales evocadas por el adjetivo y el sustantivo. No quiere esto decir que el sacerdote tenga que controlarse en presencia de la chica para no ceder a sus encantos; varias veces se insiste en que la criada no es el tipo de mujer ideal para Julián (éste estaría representado por Nucha) y, por otra parte, a Julián «la continencia le fue fácil, casi

${ }^{25}$ Carlos Feal, «La voz...», Art. cit., pág. 215.

"CUADERNOS DE ESTUDIOS GALLEGOS", Tomo XLIV, Fascículo 109, Santiago 1997. 
insensible, por lo mismo que la guardó incólume, pues sienten los moralistas que es más hacedero no pecar una vez que pecar una sola» $(\mathrm{P}$, 146). Y a pesar del cariño que el sacerdote siente hacia el hijo de Sabel, no puede impedir considerarlo un «mal retoño de tronco ruin» $(\mathrm{P}, 263)$. Carlos Feal dice acerca de este personaje que «al proyectar toda la culpa en Sabel, Julián está, pues, revelando sus prejuicios masculinos. Así entendido, Julián funciona como una especie de puente entre actitudes feministas y anti-feministas, lo que explicaría la actitud ambivalente que suscita en la narradora, quien a la vez simpatiza con él y se burla de él» ${ }^{26}$.

Si todo lo expuesto hasta ahora no fuera suficiente para mostrar a Sabel como un personaje negativo, el narrador (tendríamos que decir la narradora) toma la voz para retratarla con mayor crudeza, sometiéndola a una continua animalización y acaba por identificarla con la mujer malvada que tiene tratos con el demonio, al hacer el retrato de ésta como el de «una mujer hermosa y sensual, con pezuña de cabra» $(\mathrm{P}, 167)$; más adelante nos deja ver los pensamientos de Julián, que cree haber salvado, mediante el matrimonio, al marqués «de las garras del demonio, personificado en impúdicas barraganas» (P, 218).

Pero no acaba ahí la intromisión del narrador. Cuando en el capítulo XII de Los Pazos de Ulloa se habla de la pronta marcha de Sabel para desposarse con el gaitero, doña Emilia hace uso del estilo indirecto libre para juzgar la conducta de la mujer, que es sorprendida por el capellán una noche «en coloquios más dulces que edificantes» $(\mathrm{P}, 244)$ con su enamorado. En el capítulo XIV de La Madre Naturaleza conocemos, no sin asombro, lo que Emilia Pardo Bazán, a través del narrador, nos explica: «la exbella fregatriz Sabel, [es la] causa de tantos disturbios, pecados y tristezas» (M, 185). Resulta revelador que el narrador considere culpable de todos los males acaecidos en la novela anterior a una mujer cuyo único pecado ha sido servir de esclava a los que tuvieron algún poder sobre ella. Parece dar la razón a los que piensan que la mujer es la única culpable de los vicios de los hombres. Como apunta Teresa Cook «la mujer [...], con su recatada conducta, actúa de control del hombre ${ }^{27}$; si la

\footnotetext{
${ }^{26}$ Carlos Feal, Idem, pág. 216.

${ }^{27}$ Teresa A. Cook, El feminismo en la novela de la Condesa de Pardo Bazán, Diputación Provincial de La Coruña, 1976, pág. 158.
}

"CUADERNOS DE ESTUdIOS GALLEGOS", Tomo XLIV, Fascículo 109, Santiago 1997. 
mujer falla, semeja decir entonces el narrador, no debe extrañarnos que el hombre dé rienda suelta a sus apetitos. Pero en el trato que ambos reciben por este motivo, es la mujer la que sale perjudicada. Emilia Pardo Bazán da la impresión de compartir esta opinión, al no medir con la misma vara a don Pedro Moscoso y a Sabel. Doña Emilia se permite otras muchas veces censurar la conducta disoluta del personaje, a través de juicios moralistas y generalizadores; esto es lo que ocurre en el capítulo XVIII de Los Pazos, cuando Julián, buscando a Sabel, la encuentra saliendo de la habitación de don Pedro; la escritora, por medio del narrador, sentencia: «Las reglas psicológicas aplicables a las conciencias culpadas exigían que Sabel se turbase: quien se turbó fue Julián» (P, 303-304).

Una forma que utiliza la escritora para predisponer al lector en contra del personaje, consiste en referirse a él por medio de aumentativos que conllevan un matiz despectivo; notemos que se refiere a ella como «la frescachona Sabel» (P, 167), y más adelante, alude a su actitud «campechanota» $(\mathrm{P}, 169)$ al entrar en la estancia del sacerdote.

Otro procedimiento empleado por Pardo Bazán para denigrar más a la mujer es el que podríamos llamar de asimilación. Sabel es retratada negativamente al subrayar el amor y la devoción que siente hacia un personaje ridículo y de poca altura moral: el Gallo; de esta forma las características peyorativas del personaje son asimiladas por la mujer, que las ve como algo digno de alabanza (cap. XIV de La Madre Naturaleza). Tan amiga de sugerencias, la escritora parece dar a entender dime con quién andas y te diré quién eres.

Después de todo lo expuesto cabría preguntarse por qué la escritora se ensaña con el personaje de Sabel, por qué no hay ni un atisbo de ternura para una mujer maltratada y herida por los hombres; lo que asombra, en realidad, no es esto, sino que en unas novelas en las que la autora no pudo conservar toda la objetividad que hubiera deseado, los frecuentes juicios subjetivos se hayan empleado en degradar al personaje. Sabel es un símbolo sexual y, como hemos dicho, manifiesta su sexualidad de forma abierta, sin recatarse ni cuidar las formas. Esta actitud, que no se censura en el personaje varón, que actúa con mayor descaro que la moza, es criticada por la autora en una evidente postura antifeminista.

Otro punto importante para observar el antifeminismo de la escritora es la contradicción existente entre su pensamiento y las obras que nos ocupan, que contrasta con la idea que tradicionalmente se tiene de la escritora al basarse en sus escritos, conferencias y ensayos.

"CUADERNOS DE ESTUDIOS GALLEGOS", Tomo XLIV, Fascículo 109, Santiago 1997. 
Resulta interesante observar las generalizaciones que, acerca de la mujer, se le escapan a doña Emilia en su obra y que difieren con lo que realmente dice creer; por ejemplo, la que le hace animalizar a todo el sexo femenino debido a su gusto por la charla en voz demasiado alta: en la cocina de Sabel se reunían muchas mujeres, unas «gemían de gusto al acercarse a la deleitable llama; otras, tomando de la cintura y el huso de copo de lino, hilaban después de haberse calentado las manos [...], y todas, empezando por cuchichear bajito, acababan por charlotear como urracas» $(\mathrm{P}, 166)$. Aunque la generalización es suave, ya que podemos pensar que más que generalizar está hablándonos de aquel grupo en especial, podemos advertir que cuando la tertulia es de hombres, las conversaciones de éstos tienen la suficiente importancia para la escritora como para dar conocimiento de ellas y mostrar lo que allí se trata (la conversación el día del patrón en la mesa, la de la víspera de la caza, etc...); por el contrario, nunca asistimos a una conversación entre mujeres, quizás porque doña Emilia considera poco importantes los temas de que puedan hablar y por eso se convierten en charlas de urracas, con más ruido que fondo.

La contradicción existe también en el tema de las convenciones sociales que obligan a la mujer a permanecer en un determinado estado de disimulo e hipocresía, lo cual hace decir a Gabriel: «iQué antipática me es [...] la mentira, la convención social!», para añadir: «Convengamos en que hace falta, bueno...» y terminar diciendo: «Verdad es que todo hace falta para reprimir la bestialidad humana. A no ser por eso..., ¡crac!» (M, 275). Estas son las mismas reflexiones que se hace doña Emilia y que deja ver a través de su portavoz en La Madre Naturaleza. Cuando don Pedro Moscoso en el capítulo XI abraza a Rita, que un momento antes jugaba a escaparse de él, espera que ésta se resista; la escritora participa de lo que don Pedro hubiese pensado de su prima si así ocurriese, al apuntar: «Parecióle que la víctima no se resistía, entonces; mas debía ser errónea tan maliciosa suposición» $(\mathrm{P}, 230)$. Como bien apunta Teresa $\mathrm{Cook}^{28}$, doña Emilia no condena las normas sociales, y sería erróneo creer que es así. Se queja de la dosis de hipocresía que en ellas hay, pero sabe que en toda sociedad civilizada el hombre debe guiarse por unos principios sociales que controlen su primitivismo. La cortesía, los buenos mo-

${ }^{28}$ Teresa A. Cook, El feminismo..., Ob. cit., pág. 78.

"CUADERNOS DE ESTUdIOS GALLEGOS", Tomo XLIV, Fascículo 109, Santiago 1997. 
dales, tienen un lugar en la sociedad de La Condesa; lo que ella repudia es la hipocresía, la frivolidad y la ignorancia.

Pardo Bazán criticó siempre la falta de libertad de la mujer, pero eso no es óbice para que en Los Pazos de Ulloa, cuando Julián y Nucha planean escapar (cap. XXVII), sentencie, a través del narrador, el hecho delictivo al que el sacerdote piensa sumarse «arrebatando [...] una mujer a su legítimo dueño» (P, 389). Por mucho que la ley del siglo XIX considerara al marido con derechos sobre su esposa, creo que una mujer que estuviese en contra de semejante hecho, y doña Emilia se encuentra para muchos críticos entre las que así piensan, nunca utilizaría semejante término, a no ser que en su fuero interno no rechazase tal situación.

Con respecto a la educación de la mujer, doña Emilia relaciona la inferioridad intelectual de la mujer con causas externas a ella, pero, como afirma Pilar González ${ }^{29}$, la tesis de que el sexo masculino tiene poder de conformar el «ser de la mujer» no deja de ser paradójico viniendo de alguien que se coloca aparentemente en una posición de igualdad.

En lo que atañe al tema del divorcio, podríamos creer que una mujer que vivió separada de su marido, debido, según muchos $\operatorname{críticos}^{30}$, a las divergencias surgidas con él a raíz de la publicación de La Cuestión Palpitante, sería partidaria del divorcio; sin embargo, a fines del siglo XIX hubo en España una polémica acerca del tema, y la actitud de la Pardo Bazán, según cuanta Ronald Hilton, fue que «...elle ne savait pas bien quelle position adopter» ${ }^{31}$; lo cual la escritora, que se debate, en la vida real, entre posturas encontradas. Si esto ocurre en su vida, mayor será la contradicción en su obra, en la que imperceptiblemente se escapan ideas y comentarios que revelan una forma de pensar más verdadera. Nucha no piensa en ningún momento en la separación legal de su marido, sólo se plantea alejarse de él para evitar el imaginado daño a su hija.

En cuanto a la religión, doña Emilia, ferviente católica, no rechaza los postulados religiosos que, si bien consideran al hombre y a la mujer en un plano de igualdad, no hacen nada por la lucha en favor de esta última; si

\footnotetext{
${ }^{29}$ Pilar González, Aporías..., Ob. cit., pág. 19.

${ }^{30}$ Consúltese: Teresa A Cook, «Emilia Pardo Bazán y la educación como elemento primordial en la liberación de la mujer». Hispania, 60 (May 1977) pág. 262.

${ }^{31}$ Ronald Hilton, «Emilia Pardo Bazán et le mouvement féministe en Espagne», Bulletin Hispanique, 54 (1952), pág. 161.
}

"CUADERNOS DE ESTUdIOS GALLEGOS", Tomo XLIV, Fascículo 109, Santiago 1997. 
en las novelas de Los Pazos Julián intenta ayudar a Nucha frente a su marido, se debe sólo a la debilidad de carácter del capellán, y esta misma debilidad lo llevará a no conseguirlo. Como indica Carlos Feal al referirse a las ideas religiosas de la escritora: «La fe religiosa entró en ella en pugna no sólo con su racionalismo, sino también con sus tendencias feministas y naturalistas. Si el intento de armonizar diversas actitudes condujo a un naturalismo católico, parejamente podría hablarse de un feminismo católico» ${ }^{32}$.

Por último hay un hecho en La Madre Naturaleza que llama poderosamente la atención del lector: cuando Perucho conoce por Gabriel su parentesco con Manola (cap. XXIX), no conforme con lo que ha oído, decide preguntárselo a la persona que mejor lo puede saber; pero, contrariamente a lo que la lógica exigiría, Perucho se dirige al marqués, no a su madre. Cuesta trabajo comprender los motivos que llevaron a doña Emilia a dar este giro en el realismo de su obra, sin apenas darse cuenta, pues en ningún momento se sugiere lo errado de la conducta de Perucho; la escritora parece haberlo decidido así, como si de la cosa más natural se tratase. ¿Ha querido dar a entender algo con esto? ¿Quiso, quizás, señalar a quien consideraba culpable de la situación? En todo caso, al no hacer ninguna salvedad sobre el tema, podríamos entender que incluso en estos asuntos el hombre tiene mayor conocimiento que la mujer, y, sobre todo, mayor autoridad para corroborar con su palabra un hecho del que sólo la mujer puede dar cuenta. Afirmar tal cosa sería asegurar que el antifeminismo de Emilia Pardo Bazán late en las novelas de Los Pazos en un grado muy superior al establecido hasta este momento.

\footnotetext{
${ }^{32}$ Carlos Feal, «Religión y feminismo en la obra de Emilia Pardo Bazán», Homenaje a Juan López-Morillas, Castalia, Madrid, 1982, pág. 191.
}

"CUADERNOS DE ESTUdios GALLEGOS", Tomo XLIV, Fascículo 109, Santiago 1997. 